\title{
Effect of prefrontal and parietal tDCS on learning and recognition of verbal and non-verbal material
}

\author{
Aurélie L. Manuel, PhD, Armin Schnider, MD
}

Laboratory of Cognitive Neurorehabilitation, Division of Neurorehabilitation, Department of Clinical Neurosciences, University of Geneva and Univesity Hospital of Geneva, Switzerland

\section{Correspondence:}

Dr. Aurélie Manuel

Service de Neurorééducation

Hôpitaux Universitaires de Genève

26, av. de Beau-Séjour

1211 Geneva 14, Switzerland

Tel.: +41-22-372 3647

Fax: +41-22-372 3705

E-mail: aurelie.manuelstocker@hcuge.ch 


\section{Abstract}

Objective: Information learned in a spaced way is usually better recognized than information learned in a massed way. The brain mechanisms underlying this spacing effect remain unclear.

$\underline{\text { Methods: }}$ We applied anodal transcranial direct current stimulation (tDCS) to the left and right prefrontal (PFC) or posterior parietal (PPC) cortices to study how stimulation influences learning and retrieval of information, as evidenced by item recognition and the spacing effect, and whether the effects are lateralized according to stimulus material and site of stimulation. We devised a continuous recognition task with verbal and non-verbal stimuli repeated either immediately or after a delay. Stimulus recognition was tested 30minutes later.

$\underline{\text { Results: }}$ There was a spacing effect for both materials, which, however, was not modulated by tDCS. Nonetheless, tDCS differentially impacted memory retrieval regardless of repetition mode during learning: tDCS over the PPC during learning enhanced recognition of nonverbal material regardless of side of stimulation, while tDCS over the left PFC decreased recognition regardless of material.

Conclusions: The PPC seems to be involved specifically in the mnesic treatment of nonverbal material whereas the left PFC specifically influences learning irrespective of stimulus material.

Significance: Prefrontal and posterior parietal cortices follow different lateralization rules in recognition memory.

Keywords: Episodic memory, encoding, retrieval, transcranial direct current stimulation, posterior parietal, prefrontal, lateralization. 


\section{Introduction}

Stimuli presented in immediate succession during learning (massed repetition) are less well retained in memory than stimuli repeated after a delay (spaced repetition) (Nielsen-Bohlman and Knight, 1994, Chao et al. , 1995, Kim et al. , 2001, Kim et al. , 2008). This effect is referred to as the spacing effect (Ebbinghaus, 1885/1992). Spacing effects have been reported with verbal and non-verbal and with meaningful and meaningless material (Challis, 1993, Mammarella et al. , 2002, Russo and Mammarella, 2002, Russo et al. , 2002).

However, the brain mechanisms, including the hemispheric contributions, underlying the spacing effect remain unclear. While verbal massed repetition has been variably shown to activate the cingulate cortex (Kim et al. , 2001, 2008) or a left-lateralized parietal network (Manuel and Schnider, 2016), non-verbal massed repetition activates the left medio-temporal lobe (James et al. , 2009, Nahum et al. , 2011, Nahum et al. , 2015) or right prefrontal cortex (Manuel and Schnider, 2016).

The medio-temporal and prefrontal regions of the brain are critical areas for episodic memory (Simons and Spiers, 2003, Squire et al. , 2004). Several PET and fMRI studies also reported posterior parietal cortex (PPC) activation in episodic memory tasks (Rugg et al. , 2002, Wagner et al. , 2005, Cabeza et al. , 2008, Ciaramelli et al. , 2010). Hemispheric lateralization was repeatedly observed: There was lateralization to the left prefrontal cortex (PFC) and medio-temporal lobe (MTL) in studies using verbal information and right-lateralization for non-verbal stimuli (Kelley et al. , 1998, Wagner et al. , 1998). On a conceptual level, the hemispheric encoding retrieval asymmetry model (HERA) proposed that the left PFC would be essential for encoding, the right PFC for retrieving verbal (Shallice et al. , 1994) as well as non-verbal material (Tulving et al. , 1994). Transcranial magnetic stimulation (TMS) studies yielded mixed results. TMS to the left PFC interfered with encoding of pictures of complex scenes whereas right PFC stimulation dampened retrieval, a pattern in favour of the HERA 
model (Rossi et al. , 2001, Floel et al. , 2004, Rossi et al. , 2006). Another study showed that TMS over the left PFC interfered with encoding of verbal material and encoding of nonverbal material was disrupted by stimulation of right PFC, speaking in favor of a material specific lateralization in the PFC (Floel et al. , 2004). Finally, Sandrini et al. (2003) showed that repetitive transcranial magnetic stimulation (rTMS) to the left and the right PFC interfered with encoding of word pairs.

Although repeatedly reported in lesion studies (Kessels et al. , 2002, Ally et al. , 2008), lateralization of PPC function is less consistent in neuroimaging studies and TMS studies. Nagel et al. (2013) reported a left hemispheric lateralization for verbal memory, whereas Wagner et al. (2005) demonstrated left PPC activation in old/new recognition tasks with verbal and non-verbal stimuli. Furthermore, while Manenti et al. (2010) reported disruption of verbal memory retrieval following TMS over the left PPC, Rossi et al. (2006) observed no such effect.

Here we tested the influence of transcranial direct current stimulation (tDCS) applied over left and right PFC and PPC during encoding of verbal and non-verbal material and its effect on delayed retrieval, in particular its effect on the spacing effect. tDCS is a well-tolerated neuromodulation technique (Nitsche et al. , 2003, Brunoni et al. , 2011) where a low intensity electrical current is applied to the scalp to temporarily modulate cortical excitability. Anodal polarization augments cortical excitability while cathodal polarization diminishes it (Paulus, 2003, Nitsche and Paulus, 2011, Dayan et al. , 2013, Parkin et al. , 2015). The existence of cortical excitability modulations have been initially shown in the human motor cortex (Nitsche and Paulus, 2000, 2001) and visual cortex (Antal et al. , 2003), and only recently in higher-order cognitive functions such as memory (e.g. Shin et al. , 2015). tDCS studies have demonstrated enhanced retrieval of non-verbal material following anodal stimulation of the right PFC (Chi et al. , 2010) and improved verbal memory following anodal tDCS over the 
left PFC (Javadi and Cheng, 2013). Anodal tDCS over the left parietal cortex has also been shown to enhance verbal memory (Jacobson et al. , 2012, Jones et al. , 2014).

To assess how left and right PFC and PPC tDCS during encoding modulate verbal and nonverbal memory retrieval, including the spacing effect, we devised a continuous recognition task comprising non-verbal (meaningless geometric designs) and verbal stimuli (non-words) repeated either immediately or after a delay. Memory retrieval was tested 30 minutes later. We hypothesized that left PFC or PPC stimulation would improve recognition of verbal material whereas right PFC or PPC stimulation would enhance non-verbal mnesic processing.

\section{Methods}

\subsection{Participants}

Twenty-eight healthy, French-speaking, right-handed participants were included in the study. Two participants were excluded as they did not complete the whole experiment. The remaining 26 participants took part in the study composed of two separate experiments: half of the subjects were attributed to PPC stimulation group ( $n=13$, aged $24 \pm 5$; seven men), the other half to the PFC stimulation group ( $n=13$, aged $23 \pm 3$; four men). The two groups did not significantly differ regarding gender distribution $\left(\mathrm{X}^{2}(1)=1.42, p=0.23\right)$ or age $\left(t_{(24)}=0.68, p\right.$ $=0.51$ ). Participants gave written consent to take part in the study and were remunerated for their participation. No participant had a history of neurological or psychiatric illness. The procedures were validated by the Ethics Committee of the Canton of Geneva.

\subsection{Experimental design}

For this single-blind, sham-controlled study, participants were recruited separately for both experiments. In the first experiment, participants received tDCS over the posterior parietal 
cortex and in the second experiment they were stimulated over the prefrontal cortex.

Stimulation was delivered during the continuous recognition task (learning task). The delayed recognition task performed 30 minutes later was stimulation-free. Each participant completed three sessions: left anodal, right anodal and sham. Order of sessions was randomized within subjects and sessions were planned with at least one week between sessions to avoid carryover effects of tDCS or the task.

\subsection{Stimuli}

Stimuli were non-words (verbal material) and abstract geometrical shapes (non-verbal material). The non-words were composed of a series of five letter meaningless words (Arial, font size 100) pronounceable according to French pronunciation rules. The non-verbal material consisted of black and white stimuli representing meaningless geometric designs. These stimuli were created with a program we devised which allows producing random abstract geometric pictures. We only included stimuli that touched the 4 borders of the frame $($ size $8.7 \times 5.3 \mathrm{~cm})$ and which were composed of at least 4 different elements. To assess whether visual complexity differed among the chosen set of abstract geometric designs, an independent group of 11 participants were asked to rate visual complexity using a 7-point scale ("very simple" to "very complex"). Rating of mean visual complexity did not differ between the two learning blocks (3.6 \pm 1 block $1 ; 3.6 \pm 0.9$ block 2$)$ or the delayed recognition task $\left(3.7 \pm 0.9 ; \mathrm{F}_{(2,149)}=0.4, p=0.65\right)$.

We used meaningless stimuli to separate verbal and non-verbal components and increase the likelihood of hemispheric lateralization as it has indeed been shown that encoding of meaningful pictures may elicit verbal processing and thus prevent non-verbal processing from happening (Kelley et al. , 1998, Golby et al. , 2001). Similarly, processing real words may 
trigger image-based representations of word reading and thus be less specific to the left hemisphere (Beisteiner et al. , 1996, Binder et al. , 2005, Marinkovic et al. , 2014).

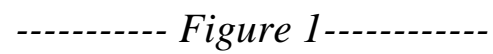

\subsection{Learning task}

Participants performed two blocks of a continuous recognition task (Fig. 1). Each block was composed of 50 abstract geometrical figures (Non-verbal material, NV) and 50 non-words (Verbal material, V). Each stimulus was repeated either immediately after the initial presentation (One-back items, $\mathrm{n}=50 ; 25 \mathrm{~V}, 25 \mathrm{NV}$ ) or following nine intervening items (Tenback items, $\mathrm{n}=50 ; 25 \mathrm{~V}, 25 \mathrm{NV}$ ). The second block consisted of the same task but with a new set of stimuli. In total, there were 100 trials for initial presentation of non-verbal stimuli (NewNV), 100 trials for initial presentation of verbal stimuli (NewV) and 50 trials for each of the repeated conditions: immediate non-verbal repetition (One-back NV), immediate verbal repetition (One-back V), spaced non-verbal repetition (Ten-back NV) and spaced verbal repetition (Ten-back V).

Stimuli were presented on a 17 -inch screen positioned at $70 \mathrm{~cm}$ from the participant (visual angle $2^{\circ}$ ). Stimuli were showed for $1000 \mathrm{~ms}$, followed by a $2000 \mathrm{~ms}$ inter-stimulus interval displaying a fixation cross. Participants were asked to respond on a response box using their right, dominant hand. Initial stimulus presentation required a right middle finger button press and stimulus repetition required a right index finger button press. Each block lasted about 10 minutes, separated by a break of 2 minutes.

\subsection{Delayed recognition task}

To test for long-term memory retention, participants were tested on a delayed recognition task 30 minutes after completing the learning task. This task comprised the totality of the 200 
stimuli previously presented in the initial learning task (50 pOneV, $50 \mathrm{pOneNV}, 50 \mathrm{pTenV}$, 50 pTenNV) plus 100 new items (50 pNewV, 50 pNewNV) randomly presented. Task duration was 15 minutes. Participants had to indicate whether stimuli had appeared in the learning task or not. Stimuli were the same for the three sessions. There was a one-week interval between each session to ensure a proper tDCS and memory wash-out.

\subsection{Data analysis}

A series of $2 \times 3 \times 2 \times 3$ mixed-model repeated measures ANOVAs with between factor Group (Parietal, Prefrontal) and within factors tDCS (Anodal L, Anodal R, Sham), Material (Verbal, Non-verbal) and Condition (New, One-back, Ten-back) were performed on accuracy (percentage of correct responses) and response time. Significant interactions were followed by simple effects at each combination of levels of the other factors. Whenever significant, post-hoc Bonferroni corrected t-tests were performed. A measure of the effect size of each result is provided with the partial eta square $\left(\eta_{\mathrm{p}}^{2}\right)$.

The spacing effect index reflects the advantage for greater recognition in the delayed recognition task of stimuli previously presented in a spaced compared to massed way and was calculated separately for verbal and non-verbal material as following: "\%Hits pTen - \%Hits pOne" which is the difference between correctly identified stimuli which have been repeated after a delay in the learning task (Hits pTen) and correctly identified items that were presented in immediate succession in the learning task (Hits pOne). Statistical differences were assessed with a $2 \times 2 \times 2$ mixed-model repeated measures ANOVA with between factor Group (Parietal, Prefrontal) and within factors tDCS (Anodal L, Anodal R, Sham) and Material (Verbal, Non-verbal). 


\subsection{Questionnaires}

During the 30 min break between the learning task and the delayed recognition task, subjects completed questionnaires on side effects (Brunoni et al. , 2011) and two ad-hoc questionnaires on health status and task difficulty.

Following each tDCS session, participants evaluated the intensity of perceptual sensation items with a 4-point rating scale $(1=$ absent, 4 = severe $)$ and indicated if the sensation was related to the stimulation or not with a 5 -point rating scale $(1=$ none, $5=$ definite $)$. The questionnaire included the following possible tDCS side-effects: headache, scalp and neck pain, tingling, burning sensation, itching, skin redness, trouble concentrating, sleepiness, acute mood change and others. This questionnaire enabled us to measure possible differences in participants' awareness between stimulation conditions. In addition following each session, participants filled in a questionnaire assessing task difficulty of the delayed recognition task with a 5-point scale ( $1=$ not difficult, 5 = very difficult $)$. Differences between conditions were assed with repeated measure ANOVAs with factors Group (Parietal, Prefrontal) and tDCS (Anodal Left, Anodal right, Sham).

\subsection{Transcranial direct current stimulation}

Direct electrical current was delivered by a battery-driven NeuroConn DC brain stimulator (NeuroConn, Ilmenau, Germany) using a pair of $35 \mathrm{~cm} 2$ rubber electrodes enclosed in salinesoaked sponges. In the parietal group, the anode electrode was placed over P3 (left PPC) or P4 (right PPC) according to the 10-20 EEG system. The cathode was placed over the contralateral supraorbital region. In the prefrontal group, the anode was placed over F3 (left dorsolateral prefrontal cortex; DLPFC) or F4 (right DLPFC). The cathode was placed over the contralateral supraorbital region. Both setups have been used successfully in memory 
studies (Fregni et al. , 2005, Javadi and Cheng, 2013, Manenti et al. , 2013). As a note of caution, it may be noted that in bilateral electrode montages with variable distance between the anode and the cathode, the current may not be distributed in an equal way in the two montages (Bikson et al. , 2012, Ruffini et al. , 2013).

A direct current of $1 \mathrm{~mA}$ with a fade-in and fade-out of $8 \mathrm{~s}$ was delivered for 24 min for the anodal stimulation conditions. The learning task started 4 minutes after the onset of the stimulation and lasted 20 minutes to ensure that tDCS had reached maximum effect at the start of the experiment (Nitsche and Paulus, 2000). For the sham condition, the electrodes were placed as for active stimulation, but the current was turned off after 30 seconds. The participants thus felt the sensation of electrical stimulation under the electrodes. This procedure was shown to reliably blind participants (Gandiga et al. , 2006). Current densities for the three sessions were maintained below the safety limit of $0.052 \mathrm{~mA} / \mathrm{cm}^{2}$ (Nitsche et al. , 2003, Iyer et al. , 2005) and the impedance was controlled by the device and kept low $(<10$ $\Omega$ ) for all stimulation sessions.

\section{Results}

\subsection{Questionnaires}

All participants well tolerated the tDCS and reported only minor side effects. Repeated measure ANOVA with factor Group and tDCS revealed that participants in the sham condition reported less side effects than in the both stimulation conditions $\left(\mathrm{F}_{(1,48)}=19.68, p<\right.$ 0.01). However, there were no significant differences in perceived difficulty between groups for any of the stimulation conditions $(p>0.33)$. 


\subsection{Learning task}

Repeated measures ANOVAs on accuracy (percentage of correct responses) and response time revealed main effects of Condition: immediate repetitions (One-back) were processed faster $\left(\mathrm{F}_{(2,48)}=126.09, p<0.01, \eta_{\mathrm{p}}{ }^{2}=0.84\right)$ and more accurately $\left(\mathrm{F}_{(2,48)}=20.60, p<0.01, \eta_{\mathrm{p}}{ }^{2}\right.$ $=0.46)$ than new items (New) or spaced repetitions (Ten-back). Regarding accuracy, there was no interaction with tDCS (all $p>0.19)$ or between-subject effects $\left(\mathrm{F}_{(1,24)}=0.001, p=\right.$ $0.97, \eta_{\mathrm{p}}^{2}<0.01$ ). For response time there was no interaction with tDCS (all $p>0.27$ ) or between-subject effects $\left(\mathrm{F}_{(1,24)}=0.85, p=0.37, \eta_{\mathrm{p}}{ }^{2}=0.03\right)$. Percentage accuracy and response time for all conditions are reported in Table 1.

Figure 2

\subsection{Delayed recognition task}

Regarding accuracy, repeated measure ANOVA indicate a spacing effect: Participants showed greater accuracy in recognizing items repeated after a delay in the learning task (pTen) and new items of the delayed recognition task ( $\mathrm{pNew}$ ) than items repeated in immediate succession (pOne) during learning $\left(\mathrm{F}_{(2,48)}=29.53, p<0.01, \eta_{\mathrm{p}}{ }^{2}=0.55\right.$; Table 1$)$. Furthermore, there was a tDCS x Material x Group interaction $\left(\mathrm{F}_{(2,48)}=4.91, p=0.01, \eta_{\mathrm{p}}{ }^{2}=\right.$ 0.17; Fig. 2A) and a Material x Condition x Group interaction $\left(\mathrm{F}_{(2,48)}=4.80, p=0.01, \eta_{\mathrm{p}}{ }^{2}=\right.$ 0.17). Post-hoc tests revealed that the tDCS x Material x Group interaction was driven by specific effects of tDCS in the PFC group and specific effects of material in the PPC group. First, in the PPC group, accuracy was greater for non-verbal compared to verbal stimuli after left $(p=0.01)$ and right $(p=0.04)$ PPC anodal stimulation. There were no simple effects for factor Group at each combination of levels of other factors (all $p>0.08$ ), nor between-subject 
effects $\left(\mathrm{F}_{(1,24)}=0.22, p=0.88, \eta_{\mathrm{p}}{ }^{2}=0.01\right)$. Secondly, anodal tDCS over the left prefrontal cortex worsened performance for verbal stimuli compared to right prefrontal tDCS $(p=0.03)$ or sham $(p=0.03)$ and a trend (considering the Bonferroni correction) for non-verbal stimuli in comparison to sham $(p=0.056)$.

Response time was faster for items previously repeated after intervening items than for new (in the delayed recognition task) or items repeated in immediate succession during learning (Main effect of Condition: $\mathrm{F}_{(2,48)}=4.79, p=0.01, \eta_{\mathrm{p}}{ }^{2}=0.16$ ) and faster for non-verbal compared to verbal stimuli (Main effect of Material: $\mathrm{F}_{(1,24)}=7.62, p=0.01, \eta_{\mathrm{p}}{ }^{2}=0.24$ ). There were no significant interactions (all $p>0.07$ ). Between-subjects effects were not significant $\left(\mathrm{F}_{(1,20)}=3.42, p=0.08, \eta_{\mathrm{p}}^{2}=0.13\right)$.

Regarding the spacing effect index (\%Hits pTen - \%Hits pOne), repeated measure ANOVA revealed that the magnitude of the spacing effect was not modulated by $\operatorname{tDCS}\left(\mathrm{F}_{(2,48)}=0.70\right.$, $\left.p=0.50, \eta_{\mathrm{p}}{ }^{2}=0.03\right)$, Material $\left(\mathrm{F}_{(1,24)}=2.02, p=0.21, \eta_{\mathrm{p}}{ }^{2}=0.08\right)$, Group $\left(\mathrm{F}_{(1,24)}=0.75, p=\right.$ $\left.0.39, \eta_{\mathrm{p}}{ }^{2}=0.03\right)$ or by an interaction between these factors $(p>0.49)$.

\section{Discussion}

This study confirms the existence of a spacing effect for non-verbal and verbal material, yet without any tDCS-related modulation of its magnitude. Rather, tDCS differentially impacted recognition memory 30 minutes later: Anodal tDCS over the posterior parietal cortex enhanced performance for non-verbal stimuli regardless of side of stimulation. Anodal tDCS over the left prefrontal cortex decreased recognition for both materials. tDCS did not influence performance during the learning task, in which accuracy was very high (82-98\% correct). 
Our results highlight the complexity of hemispheric lateralization in PPC and PFC. Our first finding confirms the role of the posterior parietal region in episodic memory, as indicated by neuroimaging studies (Wagner et al. , 2005, Skinner and Fernandes, 2007, Simons et al. , 2008). Previous tDCS and TMS studies yielded conflicting results: Stimulation of the left PPC either enhanced (Jacobson et al. , 2012, Jones et al. , 2014) or disrupted verbal memory (Manenti et al. , 2010). Using pronounceable but meaningless words (non-words), we obtained no effect of PPC stimulation. In contrast, PPC stimulation on both sides enhanced recognition of non-verbal material, a finding compatible with the parietal lobes' role in processing spatial information (Andersen, 1997, Duhamel et al. , 1997, Burgess, 2008) with little hemispheric specificity. The non-verbal stimuli used in this study were complex, meaningless, geometric designs inciting spatial processing.

Our second finding supports the role of the left PFC during encoding of verbal stimuli (Shallice et al. , 1994, Fletcher et al. , 1995, Nyberg et al. , 1996) and a trend for non-verbal stimuli (Tulving et al. , 1994, Grady et al. , 1995, Haxby et al. , 1996) presumably by maintaining information required to form episodic traces (Rossi et al. , 2011). This result is in accordance with previous studies showing that TMS to the left DLPFC interfered with encoding of verbal and non-verbal stimuli (Rossi et al. , 2001, Floel et al. , 2004, Rossi et al. , 2006). In our study, left PFC stimulation during learning led to a drop in performance during later recognition testing. While the effect is clear, our study does not allow us to attribute it unequivocally to interference during encoding. tDCS has after-effects, which may still have been active during the recognition test (Nitsche and Paulus, 2000, 2001).

The negative effect of tDCS on learning and recognition appears to be at odds with the most tDCS studies, which associate anodal stimulation to enhancement of cognitive performance (Javadi et al. , 2012, Javadi and Walsh, 2012, Javadi and Cheng, 2013). However, recent studies also report a drop in performance following anodal tDCS (Ferrucci et al. , 2008, Jones 
and Berryhill, 2012, Kaminski et al. , 2013, Zwissler et al. , 2014, Schaal et al. , 2015) or improvements following cathodal tDCS (Smirni et al. , 2015). A recent tDCS study reported a significant decrease in performance in an old/new recognition task following anodal tDCS over the left PFC during encoding of pictures (Zwissler et al. , 2014). Ferruci et al. (2008) reported a detrimental effect of anodal tDCS stimulation over the PFC during a task assessing working memory. Anodal tDCS over the prefrontal cortex may possibly increase neural signal and noise (Antal et al. , 2004, Dockery et al. , 2009, Miniussi et al. , 2013) during the encoding of verbal and non-verbal stimuli, resulting in weaker recognition in the delayed recognition task. Furthermore, normal variations in inter-individual anatomy and electrode montages determine the current flow distribution and may account for the fact that different electrode montages may lead to different patterns of current flow across the brain (Bikson et al. , 2012, Datta et al. , 2013, Truong et al. , 2013, Parazzini et al. , 2015, Labruna et al. , 2016).

We obtained lateralized effects only with prefrontal, but not with parietal stimulation. While the electrode setup was standard, it is possible that this result was influenced by the distance between the electrodes, which was longer in the parietal stimulation group. The electrical field reaches its maximum intensity towards the middle between the two electrodes (Bikson et al. , 2012, Ruffini et al. , 2013) so that the stimulation presumably extends beyond the site under the anode. This caveat does not put into question the specificity of the effects observed with the two electrode setups in this study. High density electrode montages would allow for more focal stimulation effects in the future (Bikson et al. , 2012, Ruffini et al. , 2013).

Although the behavioural results confirm previous reports showing a spacing effect for a multitude of learning materials (Cornoldi and Longoni, 1977, Challis, 1993, Braun and Rubin, 1998, Russo et al. , 1998, Mammarella et al. , 2002, Russo et al. , 2002, James et al. , 2009), its magnitude was not modulated by tDCS nor were there tDCS-induced differences in 
processing immediate versus spaced repetitions. One possible explanation is that, tDCS may not have targeted the brain regions involved in processing immediate and spaced repetitions, despite their known role in episodic memory. Neuroimaging studies indeed reported differential activations between immediate and spaced repetitions in various brain regions including left and right prefrontal, parietal, temporal, occipital or even cingulate cortex (Kim et al. , 2008, James et al. , 2009, Zhao et al. , 2015, Manuel and Schnider, 2016). Comparison with previous tDCS or TMS studies is delicate as they did not analyze recognition of stimuli learnt in a spaced and massed way separately (Javadi and Walsh, 2012, Manenti et al. , 2013) or they applied tDCS over prefrontal or posterior parietal regions before encoding (Jacobson et al. , 2012), during recognition (Manenti et al. , 2013, Pergolizzi and Chua, 2015, Pisoni et al. , 2015) or during reactivation (Javadi and Cheng, 2013), but not during encoding -with influence potentially extending to storage and recognition- as done in the present study. Hence, effects of stimulation may differ depending on when it is applied (Brunoni et al. , 2012, Hill et al. , 2016). A study comparing delayed recognition of new and old pictures, with anodal tDCS applied over the left PFC during encoding, showed a decrease in performance (Zwissler et al. , 2014) - a result similar to our study.

\section{Conclusion}

Using tDCS, our study indicates that left prefrontal cortex specifically influences memory processing regardless of material, while the posterior parietal cortices influence mnesic processing of non-verbal, but not verbal, material. The study provides evidence that functional hemispheric lateralization does not follow the same rules throughout the brain. 


\section{Acknowledgment}

This work was supported by the Swiss National Science Foundation, grant no. 32003B155947.

\section{References}

Ally BA, Simons JS, McKeever JD, Peers PV, Budson AE. Parietal contributions to recollection: electrophysiological evidence from aging and patients with parietal lesions. Neuropsychologia. 2008;46:1800-12.

Andersen RA. Multimodal integration for the representation of space in the posterior parietal cortex. Philos Trans R Soc Lond B Biol Sci. 1997;352:1421-8.

Antal A, Kincses TZ, Nitsche MA, Paulus W. Modulation of moving phosphene thresholds by transcranial direct current stimulation of V1 in human. Neuropsychologia. 2003;41:1802-7.

Antal A, Nitsche MA, Kruse W, Kincses TZ, Hoffmann KP, Paulus W. Direct current stimulation over V5 enhances visuomotor coordination by improving motion perception in humans. J Cogn Neurosci. 2004;16:521-7.

Beisteiner R, Huter D, Edward V, Koch G, Franzen P, Egkher A, et al. Brain potentials with old/new distinction of non-words and geometric figures. Electroencephalogr Clin Neurophysiol. 1996;99:517-26.

Bikson M, Rahman A, Datta A. Computational models of transcranial direct current stimulation. Clin EEG Neurosci. 2012;43:176-83.

Binder JR, Westbury CF, McKiernan KA, Possing ET, Medler DA. Distinct brain systems for processing concrete and abstract concepts. J Cogn Neurosci. 2005;17:905-17.

Braun K, Rubin DC. The spacing effect depends on an encoding deficit, retrieval, and time in working memory: evidence from once-presented words. Memory. 1998;6:37-65.

Brunoni AR, Amadera J, Berbel B, Volz MS, Rizzerio BG, Fregni F. A systematic review on reporting and assessment of adverse effects associated with transcranial direct current stimulation. Int J Neuropsychopharmacol. 2011;14:1133-45.

Brunoni AR, Nitsche MA, Bolognini N, Bikson M, Wagner T, Merabet L, et al. Clinical research with transcranial direct current stimulation (tDCS): challenges and future directions. Brain Stimul. 2012;5:175-95.

Burgess N. Spatial cognition and the brain. Ann N Y Acad Sci. 2008;1124:77-97.

Cabeza R, Ciaramelli E, Olson IR, Moscovitch M. The parietal cortex and episodic memory: an attentional account. Nat Rev Neurosci. 2008;9:613-25. 
Challis BH. Spacing effects on cued-memory tests depend on level of processing. J Exp Psychol Learn Mem Cogn. 1993;19:389-96.

Chao LL, Nielsen-Bohlman L, Knight RT. Auditory event-related potentials dissociate early and late memory processes. Electroencephalogr Clin Neurophysiol. 1995;96:157-68.

Chi RP, Fregni F, Snyder AW. Visual memory improved by non-invasive brain stimulation. Brain Res. 2010;1353:168-75.

Ciaramelli E, Grady C, Levine B, Ween J, Moscovitch M. Top-down and bottom-up attention to memory are dissociated in posterior parietal cortex: neuroimagingand and neuropsychological evidence. J Neurosci. 2010;30:4943-56.

Cornoldi C, Longoni A. The MP-DP effect and the influence of distinct repetitions on recognition of random shapes. Ital J Psychol. 1977;4:65-76.

Datta A, Dmochowski JP, Guleyupoglu B, Bikson M, Fregni F. Cranial electrotherapy stimulation and transcranial pulsed current stimulation: a computer based highresolution modeling study. Neuroimage. 2013;65:280-7.

Dayan E, Censor N, Buch ER, Sandrini M, Cohen LG. Noninvasive brain stimulation: from physiology to network dynamics and back. Nat Neurosci. 2013;16:838-44.

Dockery CA, Hueckel-Weng R, Birbaumer N, Plewnia C. Enhancement of planning ability by transcranial direct current stimulation. J Neurosci. 2009;29:7271-7.

Duhamel JR, Bremmer F, Ben Hamed S, Graf W. Spatial invariance of visual receptive fields in parietal cortex neurons. Nature. 1997;389:845-8.

Ebbinghaus H. Uber das Gedächtnis. Untersuchungen zur experimentellen Psychologie. Darmstadt: Wissenschaftliche Buchgesellschaft; 1885/1992.

Ferrucci R, Marceglia S, Vergari M, Cogiamanian F, Mrakic-Sposta S, Mameli F, et al. Cerebellar transcranial direct current stimulation impairs the practice-dependent proficiency increase in working memory. J Cogn Neurosci. 2008;20:1687-97.

Fletcher PC, Frith CD, Grasby PM, Shallice T, Frackowiak RS, Dolan RJ. Brain systems for encoding and retrieval of auditory-verbal memory. An in vivo study in humans. Brain. 1995;118:401-16.

Floel A, Poeppel D, Buffalo EA, Braun A, Wu CW, Seo HJ, et al. Prefrontal cortex asymmetry for memory encoding of words and abstract shapes. Cereb Cortex. 2004;14:404-9.

Fregni F, Boggio PS, Nitsche M, Bermpohl F, Antal A, Feredoes E, et al. Anodal transcranial direct current stimulation of prefrontal cortex enhances working memory. Exp Brain Res. 2005;166:23-30.

Gandiga PC, Hummel FC, Cohen LG. Transcranial DC stimulation (tDCS): a tool for doubleblind sham-controlled clinical studies in brain stimulation. Clin Neurophysiol. 2006;117:845-50.

Golby AJ, Poldrack RA, Brewer JB, Spencer D, Desmond JE, Aron AP, et al. Materialspecific lateralization in the medial temporal lobe and prefrontal cortex during memory encoding. Brain. 2001;124:1841-54.

Grady CL, McIntosh AR, Horwitz B, Maisog JM, Ungerleider LG, Mentis MJ, et al. Agerelated reductions in human recognition memory due to impaired encoding. Science. 1995;269:218-21.

Haxby JV, Ungerleider LG, Horwitz B, Maisog JM, Rapoport SI, Grady CL. Face encoding and recognition in the human brain. Proc Natl Acad Sci U S A. 1996;93:922-7. 
Hill AT, Fitzgerald PB, Hoy KE. Effects of Anodal Transcranial Direct Current Stimulation on Working Memory: A Systematic Review and Meta-Analysis of Findings From Healthy and Neuropsychiatric Populations. Brain Stimul. 2016;9:197-208.

Iyer MB, Mattu U, Grafman J, Lomarev M, Sato S, Wassermann EM. Safety and cognitive effect of frontal DC brain polarization in healthy individuals. Neurology. 2005;64:8725.

Jacobson L, Goren N, Lavidor M, Levy DA. Oppositional transcranial direct current stimulation (tDCS) of parietal substrates of attention during encoding modulates episodic memory. Brain Res. 2012;1439:66-72.

James C, Morand S, Barcellona-Lehmann S, Michel CM, Schnider A. Neural transition from short- to long-term memory and the medial temporal lobe: a human evoked-potential study. Hippocampus. 2009;19:371-8.

Javadi AH, Cheng P. Transcranial direct current stimulation (tDCS) enhances reconsolidation of long-term memory. Brain Stimul. 2013;6:668-74.

Javadi AH, Cheng P, Walsh V. Short duration transcranial direct current stimulation (tDCS) modulates verbal memory. Brain Stimul. 2012;5:468-74.

Javadi AH, Walsh V. Transcranial direct current stimulation (tDCS) of the left dorsolateral prefrontal cortex modulates declarative memory. Brain Stimul. 2012;5:231-41.

Jones KT, Berryhill ME. Parietal contributions to visual working memory depend on task difficulty. Front Psychiatry. 2012;3:81.

Jones KT, Gozenman F, Berryhill ME. Enhanced long-term memory encoding after parietal neurostimulation. Exp Brain Res. 2014;232:4043-54.

Kaminski E, Hoff M, Sehm B, Taubert M, Conde V, Steele CJ, et al. Effect of transcranial direct current stimulation (tDCS) during complex whole body motor skill learning. Neurosci Lett. 2013;552:76-80.

Kelley WM, Miezin FM, McDermott KB, Buckner RL, Raichle ME, Cohen NJ, et al. Hemispheric specialization in human dorsal frontal cortex and medial temporal lobe for verbal and nonverbal memory encoding. Neuron. 1998;20:927-36.

Kessels RP, Jaap Kappelle L, de Haan EH, Postma A. Lateralization of spatial-memory processes: evidence on spatial span, maze learning, and memory for object locations. Neuropsychologia. 2002;40:1465-73.

Kim M, Kim J, Kwon JS. The effect of immediate and delayed word repetition on eventrelated potential in a continuous recognition task. Brain Res Cogn Brain Res. 2001;11:387-96.

Kim MS, Kim JS, Chung CK. Neural correlates of immediate and delayed word recognition memory: an MEG study. Brain Res. 2008;1240:132-42.

Labruna L, Jamil A, Fresnoza S, Batsikadze G, Kuo MF, Vanderschelden B, et al. Efficacy of Anodal Transcranial Direct Current Stimulation is Related to Sensitivity to Transcranial Magnetic Stimulation. Brain Stimul. 2016;9:8-15.

Mammarella N, Russo R, Avons SE. Spacing effects in cued-memory tasks for unfamiliar faces and nonwords. Mem Cognit. 2002;30:1238-51.

Manenti R, Brambilla M, Petesi M, Ferrari C, Cotelli M. Enhancing verbal episodic memory in older and young subjects after non-invasive brain stimulation. Front Aging Neurosci. 2013;5:49. 
Manenti R, Tettamanti M, Cotelli M, Miniussi C, Cappa SF. The neural bases of word encoding and retrieval: A fMRI-guided transcranial magnetic stimulation study. Brain Topogr. 2010;22:318-32.

Manuel AL, Schnider A. Differential processing of immediately repeated verbal and nonverbal stimuli: an evoked-potential study. Eur J Neurosci. 2016;43:89-97.

Marinkovic K, Rosen BQ, Cox B, Hagler DJ, Jr. Spatio-temporal processing of words and nonwords: hemispheric laterality and acute alcohol intoxication. Brain Res. 2014;1558:18-32.

Miniussi C, Harris JA, Ruzzoli M. Modelling non-invasive brain stimulation in cognitive neuroscience. Neurosci Biobehav Rev. 2013;37:1702-12.

Nagel BJ, Herting MM, Maxwell EC, Bruno R, Fair D. Hemispheric lateralization of verbal and spatial working memory during adolescence. Brain Cogn. 2013;82:58-68.

Nahum L, Gabriel D, Spinelli L, Momjian S, Seeck M, Michel CM, et al. Rapid consolidation and the human hippocampus: intracranial recordings confirm surface EEG. Hippocampus. 2011;21:689-93.

Nahum L, Pignat JM, Bouzerda-Wahlen A, Gabriel D, Liverani MC, Lazeyras F, et al. Neural Correlate of Anterograde Amnesia in Wernicke-Korsakoff Syndrome. Brain Topogr. 2015;28:760-70.

Nielsen-Bohlman L, Knight R. Event-related potentials dissociate immediate and delayed memory. In: Heinze H, Münte T, Mangun G, editors. Electrophysiology: Basic and Clinical Research. Boston: Birkhauser; 1994. p. 169-83.

Nitsche MA, Liebetanz D, Lang N, Antal A, Tergau F, Paulus W. Safety criteria for transcranial direct current stimulation (tDCS) in humans. Clin Neurophysiol. 2003;114:2220-2; author reply 2-3.

Nitsche MA, Paulus W. Excitability changes induced in the human motor cortex by weak transcranial direct current stimulation. J Physiol. 2000;527:633-9.

Nitsche MA, Paulus W. Sustained excitability elevations induced by transcranial DC motor cortex stimulation in humans. Neurology. 2001;57:1899-901.

Nitsche MA, Paulus W. Transcranial direct current stimulation--update 2011. Restor Neurol Neurosci. 2011;29:463-92.

Nyberg L, McIntosh AR, Cabeza R, Habib R, Houle S, Tulving E. General and specific brain regions involved in encoding and retrieval of events: what, where, and when. Proc Natl Acad Sci U S A. 1996;93:11280-5.

Parazzini M, Fiocchi S, Liorni I, Ravazzani P. Effect of the Interindividual Variability on Computational Modeling of Transcranial Direct Current Stimulation. Comput Intell Neurosci. 2015;2015:963293.

Parkin BL, Ekhtiari H, Walsh VF. Non-invasive Human Brain Stimulation in Cognitive Neuroscience: A Primer. Neuron. 2015;87:932-45.

Paulus W. Transcranial direct current stimulation (tDCS). Suppl Clin Neurophysiol. 2003;56:249-54.

Pergolizzi D, Chua EF. Transcranial direct current stimulation (tDCS) of the parietal cortex leads to increased false recognition. Neuropsychologia. 2015;66:88-98.

Pisoni A, Turi Z, Raithel A, Ambrus GG, Alekseichuk I, Schacht A, et al. Separating recognition processes of declarative memory via anodal tDCS: boosting old item 
recognition by temporal and new item detection by parietal stimulation. PLoS One. 2015;10:e0123085.

Rossi S, Cappa SF, Babiloni C, Pasqualetti P, Miniussi C, Carducci F, et al. Prefrontal [correction of Prefontal] cortex in long-term memory: an "interference" approach using magnetic stimulation. Nat Neurosci. 2001;4:948-52.

Rossi S, Innocenti I, Polizzotto NR, Feurra M, De Capua A, Ulivelli M, et al. Temporal dynamics of memory trace formation in the human prefrontal cortex. Cereb Cortex. 2011;21:368-73.

Rossi S, Pasqualetti P, Zito G, Vecchio F, Cappa SF, Miniussi C, et al. Prefrontal and parietal cortex in human episodic memory: an interference study by repetitive transcranial magnetic stimulation. Eur J Neurosci. 2006;23:793-800.

Ruffini G, Wendling F, Merlet I, Molaee-Ardekani B, Mekonnen A, Salvador R, et al. Transcranial current brain stimulation (tCS): models and technologies. IEEE Trans Neural Syst Rehabil Eng. 2013;21:333-45.

Rugg MD, Otten LJ, Henson RN. The neural basis of episodic memory: evidence from functional neuroimaging. Philos Trans R Soc Lond B Biol Sci. 2002;357:1097-110.

Russo R, Mammarella N. Spacing effects in recognition memory: When meaning matters. Eur J Cogn Psychol. 2002;14:49-59.

Russo R, Mammarella N, Avons SE. Toward a unified account of spacing effects in explicit cued-memory tasks. J Exp Psychol Learn Mem Cogn. 2002;28:819-29.

Russo R, Parkin AJ, Taylor SR, Wilks J. Revising current two-process accounts of spacing effects in memory. J Exp Psychol Learn Mem Cogn. 1998;24:161-72.

Sandrini M, Cappa SF, Rossi S, Rossini PM, Miniussi C. The role of prefrontal cortex in verbal episodic memory: rTMS evidence. J Cogn Neurosci. 2003;15:855-61.

Schaal NK, Javadi AH, Halpern AR, Pollok B, Banissy MJ. Right parietal cortex mediates recognition memory for melodies. Eur J Neurosci. 2015;42:1660-6.

Shallice T, Fletcher P, Frith CD, Grasby P, Frackowiak RS, Dolan RJ. Brain regions associated with acquisition and retrieval of verbal episodic memory. Nature. 1994;368:633-5.

Shin YI, Foerster A, Nitsche MA. Transcranial direct current stimulation (tDCS) - application in neuropsychology. Neuropsychologia. 2015;69:154-75.

Simons JS, Peers PV, Hwang DY, Ally BA, Fletcher PC, Budson AE. Is the parietal lobe necessary for recollection in humans? Neuropsychologia. 2008;46:1185-91.

Simons JS, Spiers HJ. Prefrontal and medial temporal lobe interactions in long-term memory. Nat Rev Neurosci. 2003;4:637-48.

Skinner EI, Fernandes MA. Neural correlates of recollection and familiarity: a review of neuroimaging and patient data. Neuropsychologia. 2007;45:2163-79.

Smirni D, Turriziani P, Mangano GR, Cipolotti L, Oliveri M. Modulating Memory Performance in Healthy Subjects with Transcranial Direct Current Stimulation Over the Right Dorsolateral Prefrontal Cortex. PLoS One. 2015;10:e0144838.

Squire LR, Stark CE, Clark RE. The medial temporal lobe. Annu Rev Neurosci. 2004;27:279306.

Truong QT, Magerowski G, Blackburn GL, Bikson M, Alonso-Alonso M. Computational modeling of transcranial direct current stimulation (tDCS) in obesity: impact of head fat and dose guidelines. Neuroimage: Clinical. 2013;2:759-66. 
Tulving E, Kapur S, Craik FI, Moscovitch M, Houle S. Hemispheric encoding/retrieval asymmetry in episodic memory: positron emission tomography findings. Proc Natl Acad Sci U S A. 1994;91:2016-20.

Wagner AD, Poldrack RA, Eldridge LL, Desmond JE, Glover GH, Gabrieli JD. Materialspecific lateralization of prefrontal activation during episodic encoding and retrieval. Neuroreport. 1998;9:3711-7.

Wagner AD, Shannon BJ, Kahn I, Buckner RL. Parietal lobe contributions to episodic memory retrieval. Trends Cogn Sci. 2005;9:445-53.

Zhao X, Wang C, Liu Q, Xiao X, Jiang T, Chen C, et al. Neural mechanisms of the spacing effect in episodic memory: A parallel EEG and fMRI study. Cortex. 2015;69:76-92.

Zwissler B, Sperber C, Aigeldinger S, Schindler S, Kissler J, Plewnia C. Shaping memory accuracy by left prefrontal transcranial direct current stimulation. J Neurosci. 2014;34:4022-6. 


\section{Figure Legends}

\section{Figure 1: Task design.}

A. Participants performed two blocks of a continuous recognition task containing verbal (non-words, V) and non-verbal (meaningless geometric designs, NV) stimuli. Stimuli were presented (New) and immediately repeated (One-back; One-backNV, One-backV) or repeated after a delay (Ten-back; Ten-backNV, Ten-backV). The two blocks were composed of different stimuli and separated by a 2 min break. tDCS was applied during the continuous recognition task only. B. Thirty minutes after the completion of task A, participants performed a delayed recognition task comprising all the stimuli previously presented (pOneNV, pOneV, pTenNV, pTenV) plus new non-words (pNewV) and new meaningless designs (pNewNV).

\section{Figure 2: Behavioral results.}

A. Accuracy, B. response time in the delayed recognition task following anodal tDCS over left (AL), right (AR) hemisphere and during sham (S) stimulation for both materials. The head models indicate the electrode position for the different conditions, with black electrodes $(+)$ indicating the position of the anode and white electrodes (-) the position of the cathode. The left part shows results of the prefrontal group, the right part refers to the parietal group. Responses for New, One-back and Ten-back are collapsed. Bars show means and standard error mean. $* \mathrm{p}<0.05, * * \mathrm{p}<0.01$. The grey $*$ indicates a trend considering the Bonferroni correction. 
A Continuous recognition task

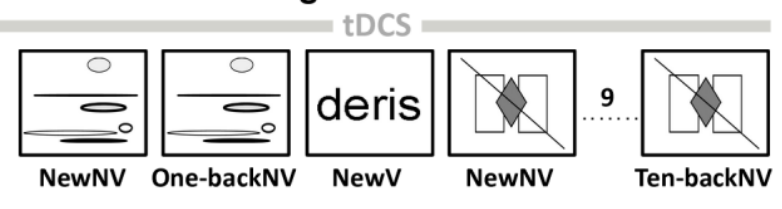

--- 30 min ---

B Delayed recognition task

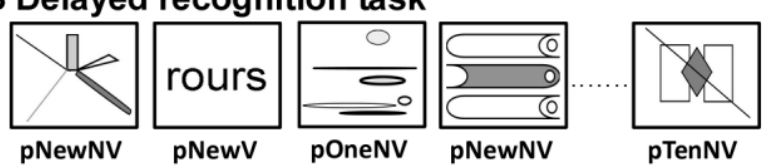




\section{A. Accuracy}

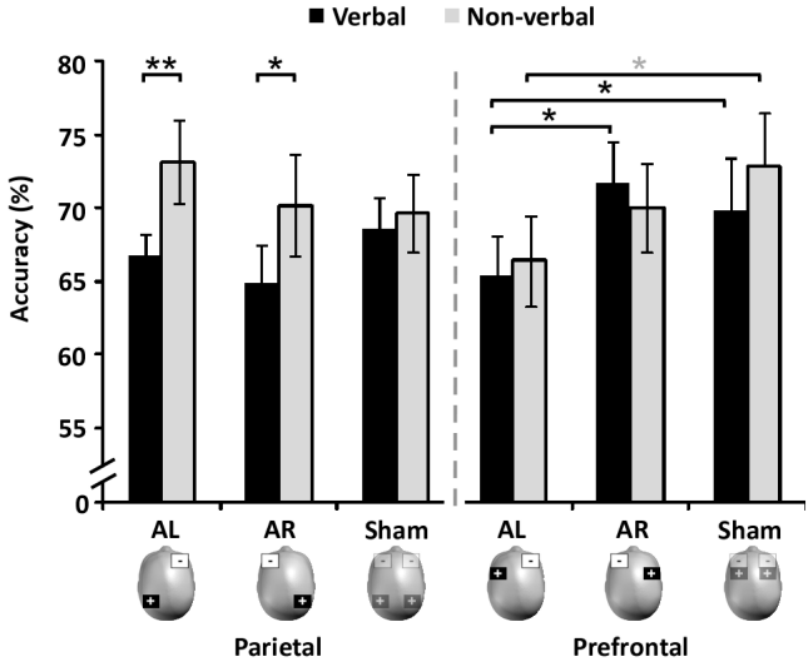

B. Response time

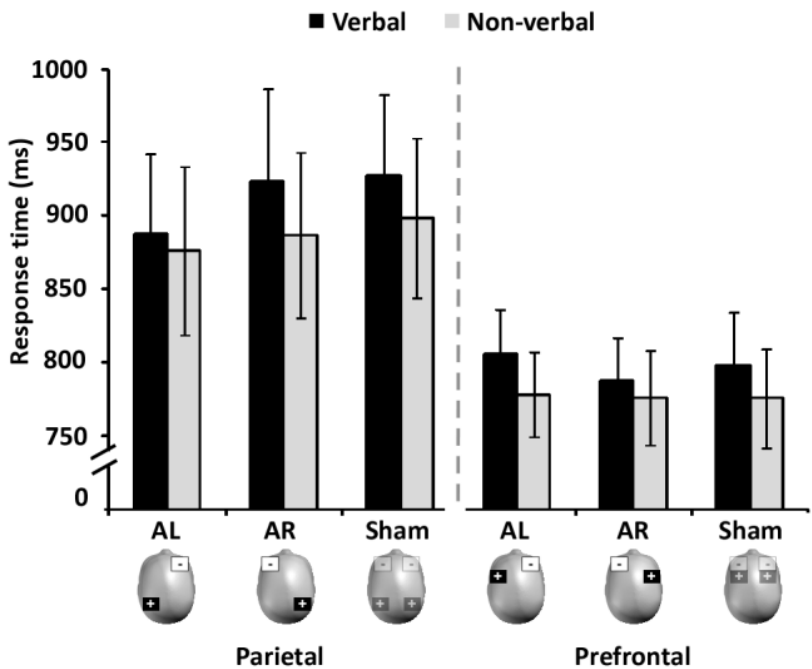




\begin{tabular}{|c|c|c|c|c|c|c|c|c|}
\hline \multicolumn{3}{|c|}{ A. Learning task } & \multicolumn{3}{|c|}{ Verbal } & \multicolumn{3}{|c|}{ Non-verbal } \\
\hline & & & New & $\begin{array}{l}\text { One- } \\
\text { back }\end{array}$ & $\begin{array}{l}\text { Ten- } \\
\text { back }\end{array}$ & NewV & $\begin{array}{l}\text { One- } \\
\text { Back }\end{array}$ & $\begin{array}{l}\text { Ten- } \\
\text { back }\end{array}$ \\
\hline \multirow[t]{6}{*}{ Accuracy } & \multirow[t]{3}{*}{ parietal } & $\begin{array}{l}\text { Anodal } \\
\text { left }\end{array}$ & $95 \pm 1$ & $99 \pm 1$ & $87 \pm 2$ & $95 \pm 1$ & $98 \pm 1$ & $90 \pm 2$ \\
\hline & & $\begin{array}{l}\text { Anodal } \\
\text { right }\end{array}$ & $88 \pm 5$ & $92 \pm 5$ & $84 \pm 5$ & $87 \pm 5$ & $90 \pm 5$ & $85 \pm 5$ \\
\hline & & Sham & $95 \pm 1$ & $98 \pm 1$ & $86 \pm 3$ & $93 \pm 2$ & $99 \pm 1$ & $89 \pm 4$ \\
\hline & \multirow[t]{3}{*}{ prefrontal } & $\begin{array}{l}\text { Anodal } \\
\text { left }\end{array}$ & $93 \pm 2$ & $96 \pm 3$ & $83 \pm 5$ & $95 \pm 1$ & $93 \pm 3$ & $82 \pm 5$ \\
\hline & & $\begin{array}{l}\text { Anodal } \\
\text { right }\end{array}$ & $93 \pm 2$ & $97 \pm 1$ & $89 \pm 3$ & $95 \pm 2$ & $96 \pm 2$ & $86 \pm 3$ \\
\hline & & Sham & $95 \pm 1$ & $97 \pm 1$ & $86 \pm 3$ & $95 \pm 1$ & $96 \pm 1$ & $85 \pm 4$ \\
\hline \multirow[t]{6}{*}{ RT } & \multirow[t]{3}{*}{ parietal } & $\begin{array}{l}\text { Anodal } \\
\text { left }\end{array}$ & $795 \pm 59$ & $646 \pm 59$ & $793 \pm 55$ & $812 \pm 63$ & $646 \pm 62$ & $775 \pm 63$ \\
\hline & & $\begin{array}{l}\text { Anodal } \\
\text { right }\end{array}$ & $762 \pm 64$ & $620 \pm 55$ & $745 \pm 59$ & $775 \pm 64$ & $617 \pm 57$ & $748 \pm 59$ \\
\hline & & Sham & $771 \pm 53$ & $649 \pm 54$ & $770 \pm 51$ & $786 \pm 50$ & $649 \pm 56$ & $764 \pm 51$ \\
\hline & \multirow[t]{3}{*}{ prefrontal } & $\begin{array}{l}\text { Anodal } \\
\text { left }\end{array}$ & $728 \pm 34$ & $595 \pm 20$ & $739 \pm 23$ & $709 \pm 26$ & $604 \pm 22$ & $739 \pm 26$ \\
\hline & & $\begin{array}{l}\text { Anodal } \\
\text { right }\end{array}$ & $719 \pm 27$ & $586 \pm 14$ & $714 \pm 17$ & $711 \pm 23$ & $581 \pm 19$ & $722 \pm 20$ \\
\hline & & Sham & $721 \pm 33$ & $589 \pm 20$ & $739 \pm 25$ & $727 \pm 30$ & $596 \pm 19$ & $726 \pm 24$ \\
\hline
\end{tabular}


page - 26

\begin{tabular}{|c|c|c|c|c|c|c|c|c|}
\hline \multicolumn{3}{|c|}{ B. Delayed recognition task } & \multicolumn{3}{|c|}{ Verbal } & \multicolumn{3}{|c|}{ Non-verbal } \\
\hline & & & New & $\begin{array}{l}\text { One- } \\
\text { back }\end{array}$ & $\begin{array}{l}\text { Ten- } \\
\text { back }\end{array}$ & NewV & $\begin{array}{l}\text { One- } \\
\text { Back }\end{array}$ & $\begin{array}{l}\text { Ten- } \\
\text { back }\end{array}$ \\
\hline \multirow[t]{6}{*}{ Accuracy } & \multirow[t]{3}{*}{ parietal } & $\begin{array}{l}\text { Anodal } \\
\text { left }\end{array}$ & $76 \pm 4$ & $58 \pm 3$ & $66 \pm 3$ & $79 \pm 4$ & $63 \pm 4$ & $77 \pm 3$ \\
\hline & & $\begin{array}{l}\text { Anodal } \\
\text { right }\end{array}$ & $80 \pm 3$ & $53 \pm 5$ & $61 \pm 5$ & $79 \pm 3$ & $59 \pm 5$ & $72 \pm 5$ \\
\hline & & Sham & $82 \pm 3$ & $57 \pm 3$ & $66 \pm 4$ & $81 \pm 3$ & $57 \pm 5$ & $70 \pm 4$ \\
\hline & \multirow[t]{3}{*}{ prefrontal } & $\begin{array}{l}\text { Anodal } \\
\text { left }\end{array}$ & $76 \pm 5$ & $55 \pm 6$ & $65 \pm 5$ & $86 \pm 2$ & $50 \pm 4$ & $63 \pm 6$ \\
\hline & & $\begin{array}{l}\text { Anodal } \\
\text { right }\end{array}$ & $80 \pm 4$ & $61 \pm 5$ & $74 \pm 5$ & $86 \pm 3$ & $54 \pm 5$ & $70 \pm 5$ \\
\hline & & Sham & $79 \pm 3$ & $59 \pm 6$ & $71 \pm 5$ & $87 \pm 2$ & $60 \pm 5$ & $71 \pm 5$ \\
\hline \multirow[t]{6}{*}{ RT } & \multirow[t]{3}{*}{ parietal } & $\begin{array}{l}\text { Anodal } \\
\text { left }\end{array}$ & $885 \pm 53$ & $890 \pm 26$ & $888 \pm 56$ & $916 \pm 64$ & $865 \pm 56$ & $847 \pm 56$ \\
\hline & & $\begin{array}{l}\text { Anodal } \\
\text { right }\end{array}$ & $927 \pm 57$ & $945 \pm 72$ & $900 \pm 66$ & $933 \pm 61$ & $877 \pm 66$ & $851 \pm 54$ \\
\hline & & Sham & $948 \pm 56$ & $918 \pm 67$ & $917 \pm 56$ & $932 \pm 51$ & $896 \pm 64$ & $867 \pm 55$ \\
\hline & \multirow[t]{3}{*}{ prefrontal } & $\begin{array}{l}\text { Anodal } \\
\text { left }\end{array}$ & $822 \pm 54$ & $815 \pm 26$ & $783 \pm 21$ & $766 \pm 28$ & $803 \pm 31$ & $767 \pm 28$ \\
\hline & & $\begin{array}{l}\text { Anodal } \\
\text { right }\end{array}$ & $811 \pm 52$ & $797 \pm 28$ & $755 \pm 20$ & $777 \pm 37$ & $799 \pm 31$ & $753 \pm 31$ \\
\hline & & Sham & $797 \pm 44$ & $811 \pm 40$ & $786 \pm 32$ & $786 \pm 34$ & $788 \pm 39$ & $753 \pm 31$ \\
\hline
\end{tabular}

Table 1. Behavioral results (mean \pm SEM) for the learning task and delayed recognition task. 